\title{
Respon Pertumbuhan Bibit Kopi Arabika (Coffea arabica L.) Varietas Ateng Keumala akibat Pemberian Pupuk Organik Cair Buah-buahan dan Dosis Pupuk Fosfor
}

\author{
(Response to Growth of Arabika Coffee Seeds with Varieties (Coffea arabica L.) or Keumala \\ by Giving Liquid Organic Fertilizer and Phosphorus Fertilizer Dosage)
}

\author{
Ainul Marziah ${ }^{1}$, Nurhayati $^{1}$, Erida Nurahmi ${ }^{1}{ }^{*}$ \\ ${ }^{1}$ Jurusan Agroteknologi, Fakultas Pertanian, Universitas Syiah Kuala \\ *erida.riri@ymail.
}

\begin{abstract}
Abstrak. Tujuan penelitian ini untuk mengetahui pengaruh konsentrasi pupuk organik cair dari buah-buahan dan dosis pupuk fosfor terhadap pertumbuhan bibit kopi arabika varietas Ateng Keumala, serta interaksi antara konsentrasi pupuk organik cair dan dosis pupuk fosfor. Penelitian ini dilaksanakan di Batang Beranun Kecamatan Bandar Bener Meriah dan Laboratorium Fisiologi Tumbuhan Fakultas Pertanian Universitas Syiah Kuala Darussalam Banda Aceh pada tanggal 1 Juli sampai 30 September 2018. Penelitian ini menggunakan Rancangan Acak Kelompok (RAK) pola faktorial dengan 2 faktor yaitu pengaruh konsentrasi pupuk organik cair buah-buahan dengan 3 taraf yaitu, Kontrol, $40 \mathrm{ml} / \mathrm{L}$ air dan $80 \mathrm{ml} / \mathrm{L}$ air. Dosis pupuk fosfat terdiri atas 3 taraf yaitu, $2 \mathrm{~g} /$ polibag, $4 \mathrm{~g} /$ polibag, dan $6 \mathrm{~g} /$ polibag. Hasil penelitian menunnjukkan bahwa pupuk organik cair berpengaruh sangat nyata terhadap berat berangkasan basah akar, berpengaruh nyata terhadap tinggi tanaman umur 30, 60, 90 HSPT, panjang akar, berat berangkasan kering tajuk. Berpengaruh tidak nyata pada diameter pangkal batang, berat berangkasan basah tajuk dan berat berangkasan kering akar. Pertumbuhan bibit Kopi Arabika terbaik terdapat pada perlakuan pupuk organik cair konsentrasi $80 \mathrm{ml} / \mathrm{L}$ air. Dosis pupuk fosfat berpengaruh sangat nyata terhadap tinggi tanaman umur 60 dan 90 HSPT dan berat berangkasan basah akar, berpengaruh nyata terhadap berat berangkasan basah tajuk. Namun tidak berpengaruh pada tinggi tanaman umur 30 HSPT, diameter pangkal batang, panjang akar, berat berangkasan kering tajuk dan berat berangkasan kering akar. Pertumbuhan bibit Kopi Arabika terbaik terdapat pada perlakuan dosis pupuk fosfat $6 \mathrm{~g} /$ polybag. Terdapat interaksi yang tidak nyata antara konsentrasi pupuk organik cair dan dosis pupuk fosfat pada semua parameter.
\end{abstract}

Kata kunci : Kopi Arabika, Dosis Pupuk Fosfor, Konsentrasi Pupuk Organik Cair

\begin{abstract}
The purpose of this study was to determine the effect of the concentration of liquid organic fertilizer from fruits and phosphorus fertilizer dosage on the growth of Arabica coffee seeds at the Ateng Keumala variety, as well as the interaction between the concentration of liquid organic fertilizer and phosphorus fertilizer dose. This research was carried out in Batang Beranun, Bandar Bener Meriah Subdistrict and Laboratory of Plant Physiology, Faculty of Agriculture, Syiah Kuala Darussalam University, Banda Aceh on July 1 to September 30, 2018. This study used a factorial randomized block design with 2 factors namely the effect of organic fertilizer concentration liquid fruits with 3 levels, namely, Control, $40 \mathrm{ml} / \mathrm{L}$ water and $80 \mathrm{ml} / \mathrm{L}$ water. The dose of phosphate fertilizer consists of 3 levels, namely, $2 \mathrm{~g} /$ polybag, $4 \mathrm{~g} /$ polybag, and $6 \mathrm{~g} /$ polybag. The results showed that liquid organic fertilizer had a very significant effect on the weight of wet root roots, significantly affected plant age 30,60, 90 HSPT, root length, canopy dry weight. Not significant effect on stem diameter, canopy wet weight and root dry weight. The best growth of Arabica Coffee seeds is found in the $80 \mathrm{ml} / \mathrm{L}$ water concentration of liquid organic fertilizer. The dose of phosphate fertilizer has a very significant effect on plant age 60 and 90 HSPT and the weight of wet rooted roots, has a significant effect on canopy wet weight. However, it did not affect plant height at 30 HSPT, stem diameter, root length, canopy dry weight and root dry weight. The best growth of Arabica Coffee seedlings is found in the treatment of $6 \mathrm{~g}$ phosphate fertilizer / poly bag. There was no significant interaction between the concentration of liquid organic fertilizer and phosphate fertilizer dosage on all parameters.
\end{abstract}

Keywords: Arabica Coffee, Dosage of Fertilizer for Phosphorus, Liquid Organic Fertilizer Concentration

\section{PENDAHULUAN}

Kopi (Coffea arabica L.) merupakan tanaman perkebunan sebagai bahan minuman yang sudah lama dibudidayakan di Indonesia. Aroma harum, rasa khas nikmat, serta khasiatnya yang menyegarkan badan membuat kopi cukup akrab di lidah dan banyak digemari. Tanaman kopi dikenal sejak tahun 1696, yang didatangkan oleh pemerintah Hindia Belanda. Jenis kopi yang pertama kali ditanam di Indonesia adalah kopi Arabika. 
Di Indonesia, kopi yang dikenal ada tiga jenis yaitu kopi Arabika, kopi Robusta dan kopi Liberika. Kelompok kopi yang dikenal memiliki nilai ekonomis yang lebih tinggi dan di perdagangkan secara komersial adalah kopi Arabika dan Robusta (Najiyati dan Danarti, 2010).

Kabupaten Bener Meriah dan Aceh Tengah di Provinsi Aceh merupakan daerah penanaman kopi Arabika terluas di Indonesia, sehingga kopi telah menjadi komoditi unggulan yang menjadi andalan sumber pendapatan masyarakat dan pemerintah daerah. Hingga saat ini diperkirakan luas areal penanaman kopi di kedua Kabupaten tersebut diperkirakan telah mencapai 85.786 hektar dengan perincian 46.296 hektar terdapat di Kabupaten Aceh Tengah dan sisanya seluas 39.490 hektar di Kabupaten Bener Meriah. Dari luasan tersebut diatas sekitar $85 \%$ jenis Arabika dan sisanya $15 \%$ jenis Robusta (Falahuddin et al., 2016).

Produksi kopi Arabika yang tinggi sangat ditentukan oleh ketersediaan bahan tanam (bibit) yang baik dan sehat. Oleh karena itu teknik pembibitan sangat penting diperhatikan khususnya media tanam dan pemupukan bibit. Media tanam memegang peran penting untuk mendapatkan bibit yang baik. Menurut Sutedjo (1986), media tanam yang baik mempunyai agregat yang mantap, tekstur lempung berliat, kapasitas menahan air yang cukup baik dan total pori yang optimal, bebasdarinematoda ataucendawanakar. Selain itu media harus memiliki kesuburan tanah yang tinggi, mengandung bahan organik yang tinggi serta tidak terdapat zat beracun.

Pertumbuhan tanaman juga sangat dipengaruhi oleh tersedianya unsur hara makro dan mikro. Apabila kekurangan salah satu dari unsur-unsur hara tersebut tanaman akan memperlihatkan gejala defisiensi. Untuk mengatasi gejala tersebut dapat dilakukan usaha pemupukan dengan teknik yang tepat dan dosis yang sesuai. Secara umum pupuk dapat dibagi menjadi dua jenis, yaitu pupuk organik yang berasal dari alam dan pupuk anorganik yang berasal dari pupuk buatan.

Pupuk organik secara fisik ada dua macam yaitu pupuk organik padat dan pupuk organik cair. Penggunaan pupuk organik dapat memberikan beberapa manfaat yaitu menyediakan unsur hara makro dan mikro bagi tanaman. Pelepasan unsur hara organik berbeda dengan pupuk kimia, pelepasan unsur hara organik akan semakin baik apabila dibantu dengan aktivitas mikroorganisme (Isnaini, 2006).

Menurut Hanolo (1997) pemberian pupuk organik cair harus memperhatikan konsentrasi yang diaplikasikan terhadap tanaman yang dibudidaya. Penggunaan konsentrasi pupuk organik cair yang tepat dapat memperbaiki pertumbuhan, mempercepat panen, memperpanjang masa atau umur produksi dan dapat meningkatkan hasil tanaman (Rizqiani et al. 2007).

Hasil penelitian Dewantara et al,. (2015), menunjukkan bahwa perlakuan pupuk organik cair dari limbah buah-buahandengan konsentrasi $40 \mathrm{ml} / \mathrm{L}$ air berpengaruh nyata pada peubah tinggi tanaman, diameter batang, total luas daun, volume akar, bobot kering tajuk dan bobot kering akar bibit tanaman kopi. Selannjutnya hasil penelitian Deby (2011), menunjukkan bahwa pemberian pupuk organik cair dari buah konsentrasi50 ml/L air memberikan pengaruh sangat nyata pada bibit tanaman kopi umur dua bulan terhadap tinggi tanaman, diameter batang, dan jumlah daun.

Hasil penelitian Lubis et al., (2015) menunjukkan bahwa perlakuan pemberian pupuk organik cair dari sisa tanaman sayuran berpengaruh tidak nyata terhadap semua parameter, namun konsentrasi POC terbaik diperoleh dari perlakuan $40 \mathrm{cc} / \mathrm{L}$ air.

Selain pupuk organik, untuk mencukupi kebutuhan unsur hara makro dan mikro, tanaman juga membutuhkan pupuk anorganik yang berasal dari pupuk buatan. Pupuk NPK merupakan salah satu jenis pupuk anorganik yang perlu diberikan pada tanaman kopi mulai dari pembibitan untuk menjamin menghasilkan bibit yang baik dan sehat, diharapkan dapat 
dihasilkan pertumbuhan dan produksi tanaman dewasa yang baik. Dalam pemupukan tanaman, banyak hal yang perlu diperhatikan salah satu diantaranya adalah penetapan dosis pemupukan. Ketidaktepatan dan ketidakseimbangan dosis pemupukan atau penambahan unsur hara dapat menghambat ketersediaan unsur lain yang pada akhirnya dapat berakibat buruk pada tanaman.

Unsur P merupakan hara utama (primer) kedua setelah $\mathrm{N}$ yang berperan dalam metabolisme dan proses mikrobiologi tanah dan mutlak diperlukan baik oleh mikroba tanah maupun tanaman. Unsur $\mathrm{P}$ juga berperan dalam pembentukan lemak dan albumin tanaman serta perkembangan akar, khususnya lateral dan akar halus berserabut. Jadi, ketersediaan unsur P di dalam tanah menjadi sangat penting bagi tanaman (Widawati dan Kanti, 2000).

Pemupukan dilakukan sesuai dengan umurnya, untuk umur bibit 1 sampai 3 bulan pemupukan dilakukan dengan caramembenamkan atau melarutkan pupuk ke dalam air sebanyak $1 \mathrm{~g}$ Urea $+2 \mathrm{~g}$ TSP $+2 \mathrm{~g} \mathrm{KCl}$ per tanaman, (Mawardi, 2008). Dosis pupuk SP-36 untuk bibit tanaman kopi yang berumur 3 bulan sebanyak $5 \mathrm{~g} / \mathrm{m}^{2}$, pada umur 5 bulan diberikan sebanyak $10 \mathrm{~g} / \mathrm{m}^{2}$, dan pada umur 7 bulan diberikan sebanyak $15 \mathrm{~g} / \mathrm{m}^{2}$. (Najiyati dan Danarti, 2010).

Berdasarkan pembahasan tersebut, maka perlu dilakukan penelitian tentang respon pertumbuhan bibit kopi arabika (Coffea arabica L.) varietas ateng keumala dengan pemberian pupuk organik cair dari buah-buahan dan dosis pupuk fosfat di dataran tinggi Kabupaten Bener Meriah.

\section{METODE PENELITIAN}

\section{Tempat dan Waktu Penelitian}

Penelitian ini dilaksanakan di Batang Beranun Kecamatan Bandar Kabupaten Bener Meriah dan Laboratorium Fisiologi Tumbuhan Fakultas Pertanian Universitas Syiah Kuala pada 1 Juli sampai dengan 30 September 2018.

\section{Alat dan Bahan}

Alat

Alat yang digunakan pada penelitian ini adalah cangkul, ayakan, gembor, bambu, paku, paranet, wadah pembuatan pupuk organik cair, gelas ukur $500 \mathrm{ml}$, meteran, jangka sorong, pisau silet, pisau, gunting, timbangan, kamera, oven, saringan, dan alat tulis.

\section{Bahan}

Bahan yang digunakan dalam penelitian ini bibit kopi arabika varietas Ateng Keumala umur 1 bulan dengan pertumbuhan seragam sebanyak 81 bibit dari BPTP-KP Gayo, buahbuahan yang berasal dari limbah pedagang buah, tanah top soil jenis Andisol, SP-36 0,324 kg, polibag volume $5 \mathrm{~kg}(30 \mathrm{~cm}$ x $35 \mathrm{~cm})$ sebanyak 81 polibag, kertas label, dan amplop.

\section{Rancangan Percobaan}

Penelitian ini menggunakan Rancangan Acak Kelompok ( RAK) pola faktorial dengan 2 faktor dan 3 ulangan. Faktor pertama yaitu konsentrasi pupuk organik cair buahbuahan (B) terdiri atas 3 taraf yaitu: $B_{0}=$ Kontrol (tanpa pupuk organik cair), $B_{1}=40 \mathrm{ml} / \mathrm{L}$ air, $\mathrm{B}_{2}=80 \mathrm{ml} / \mathrm{L}$ air. Faktor kedua dosis pupuk fosfor $(\mathrm{P})$ terdiri atas 3 taraf yaitu: $\mathrm{P}_{1}=2$ $\mathrm{g} /$ polibag, $\mathrm{P}_{2}=4 \mathrm{~g} /$ polibag, $\mathrm{P}_{3}=6 \mathrm{~g} /$ polibag.

Secara keseluruhan terdapat 9 kombinasi perlakuan dengan 3 kali ulangan, sehingga diperoleh 27 unit percobaan, setiap unit terdiri dari 3 polibag dan setiap polibag terdiri dari 1 tanaman sehingga keseluruhan terdapat 81 unit percobaan.

\section{Pelaksanaan Penelitian \\ Pembuatan Naungan}


Bahan yang digunakan untuk pembuatan naungan menggunakan bambu sebagai tiang dan paranet intensitas cahaya $60 \%$ sebagai atap. Ukuran panjang naungan $10 \mathrm{~m}$ dan lebar 5 $\mathrm{m}$. Atap naungan dibuat dengan ketinggian $1,2 \mathrm{~m}$ arah timur dan $90 \mathrm{~cm}$ arah barat, agar penyinaran pada pagi hari lebih optimal.

\section{Persiapan Media Tanam}

Media tanam yang digunakan adalah tanah jenis Andisol yang diambil dari kebun Percobaan Universitas Farm Unsyiah Stasiun Bener Meriah. Persemaian benih dilakukan 1 bulan sebelum pindah tanam oleh BPTP - KP Gayo. Tanah di tumbuk halus dan di kering anginkan kemudian di masukkan ke dalam polibag ukuran $30 \mathrm{~cm}$ x $35 \mathrm{~cm}$ dengan volume 5 $\mathrm{kg}$.

\section{Pemindahan Bibit ke Media Tanam}

Bibit kopi yang sudah berumur 1 bulan, dengan pertumbuhan seragam seperti tinggi tanaman, diameter batang dan jumlah daun dipindahkan dari media pembibitan ke dalam media tanam penelitian. Pada saat pemindahan bibit untuk mengganti dari polibag, dilakukan dengan hati-hati agar tidak merusak akar. Polibag dipotong menggunakan pisau selanjutnya bibit di tanam kembali ke polibag penelitian dengan ukuran $30 \mathrm{~cm}$ x $35 \mathrm{~cm}$ volume $5 \mathrm{~kg}$.

\section{Pembuatan pupuk organik cair dari buah-buahan}

Buah-buahan dikumpulkan dari limbah atau tidak digunakan lagi dari pedagang buah sebanyak $20 \mathrm{~kg}$ yang meliputi semua jenis buah seperti mangga, alpukat, jeruk, buah naga, wortel, pepaya, jambu biji dan semangka. Kemudian buah-buahan tersebut dipotong dan dimasukkan ke dalam wadah yang bagian bawahnya sudah di lubangi untuk mengeluarkan cairan dan ditampung, ditambah gula merah sebanyak $1 \mathrm{~kg}$ dan diaduk rata. Wadah ditutup rapat dan disimpan ditempat yang teduh. Setelah beberapa hari, buah akan mengeluarkan cairan, di tunggu selama 1 minggu atau hingga semua cairan pada buah keluar, selanjutnya disaring. Masukkan cairan kedalam botol kemasan. Pupuk organik cair dibuat satu tahap untuk 5 kali pemakaian, disimpan di tempat teduh dan tidak terkena cahaya matahari langsung agar mikroorganisme didalamnya tidak mati.

\section{Aplikasi Pemupukan}

\section{Aplikasi pupuk organik cair dari buah-buahan}

Pupuk organik cair (POC) buah-buahan diberikan dengan cara dilarutkan dengan air dan disiram di pangkal batang bibit. Pemupukan diberikan 2 minggu sekali dengan total pemberian 5 kali selama 3 bulan yaitu pada 15 HSPT, 30 HSPT, 45 HSPT, 60 HSPT, dan 75 HSPT dengan konsentrasi sesuai perlakuan yang dicobakan, yaitu tanpa pemupukan (kontrol), $40 \mathrm{ml} / \mathrm{L}$ air, $80 \mathrm{ml} / \mathrm{L}$ air dengan cara di larutkan ke dalam air dan disiramkan ke tanaman. Proses pelarutan untuk perlakuan konsentrasi $40 \mathrm{ml} / \mathrm{L}$ air, dilakukan dengan cara dilarutkan $40 \mathrm{ml}$ pupuk organik cari kedalam air sebanyak $960 \mathrm{ml}$, kemudian diberikan $250 \mathrm{ml} /$ tanaman. Pada perlakuan konsentrasi $20 \mathrm{ml} / \mathrm{L}$ air, dilakukan dengan cara dilarutkan $80 \mathrm{ml}$ pupuk organik cari kedalam air sebanyak $920 \mathrm{ml}$, kemudian diberikan $250 \mathrm{ml} /$ tanaman. Total keseluruhan POC yang dibutuhkan adalah 16,2 liter.

\section{Aplikasi pupuk SP-36}

Fosfor yang digunakan adalah pupuk SP-36 sebanyak 324 g, aplikasi dilakukan dengan cara setiap perlakuan dilarutkan kedalam air sebanyak $250 \mathrm{ml} /$ tanaman, kemudian disiram ke pangkal batang tanaman. Pupuk SP-36 diberikan satu kali yaitu pada 7 hari setelah pindah tanam (HSPT).

\section{Pemeliharaan Tanaman}

Pemeliharaan tanaman meliputi penyiraman yang dilakukan dua kali sehari yaitu pagi dan sore hari atau disesuaikan dengan kondisi lapangan. Penyiangan dilakukan secara manual dengan mencabut rumput yang tumbuh dalam pot dan plot tempat pembibitan. Pengendalian 
hama kutu putih (Pseudococcus citri Risso) dilakukan secara manual dengan mengambil dan membuang hama yang terdapat diareal penelitian.

\section{Bongkar Tanaman}

Bibit yang sudah berumur 4 bulan ( 1 bulan selama pembibitan dan 3 bulan dalam penelitian) dibongkar untuk diamati parameter pertumbuhan bibit selama penelitian. Parameter pengamatan yang diambil berupa tinggi tanaman, diameter pangkal batang, panjang akar, berat berangkasan basah tajuk, berat berangkasan basah akar, berat berangkasan kering tajuk, berat berangkasan kering akar. Pembongkaran dilakukan dengan cara menggunting polybag dan membersihkan tanah dari akar tanaman.

\section{Pengamatan}

Pengamatan pertama dilakukan pada saat bibit dipindah tanam ke polybag penelitian. Parameter penelitian tanaman terdiri dari tinggi tanaman, diameter pangkal batang, panjang akar, berat berangkasan basah tajuk, berat berangkasan basah akar, berat berangkasan kering tajuk, berat berangkasan kering akar.

\section{HASIL DAN PEMBAHASAN}

\section{Hasil Penelitian}

Rekapitulasi hasil analisis ragam (Uji F) pengaruh konsentrasi pupuk organik cair dan dosis pupuk fosfat terhadap pertumbuhan bibit kopi arabika dapat dilihat pada Tabel 1.

Tabel 1. Rekapitulasi Hasil Analisis Ragam (Uji F) pengaruh Konsentrasi Pupuk Organik Cair dan Dosis Pupuk Fosfat terhadap Pertumbuhan Bibit Kopi Arabika

\begin{tabular}{|c|c|c|c|c|}
\hline \multirow[b]{2}{*}{ Parameter Pengamatan } & \multicolumn{3}{|c|}{ Perlakuan } & \multirow[b]{2}{*}{$\mathrm{KK}(\%)$} \\
\hline & $\begin{array}{c}\text { Pupuk } \\
\text { Organik } \\
\text { Cair } \\
\text { (B) }\end{array}$ & $\begin{array}{l}\text { Pupuk } \\
\text { Fosfor } \\
\text { (P) }\end{array}$ & $\mathrm{BxP}$ & \\
\hline Tinggi Tanaman 30 HSPT $(\mathrm{cm})$ & $*$ & $\operatorname{tn}$ & tn & 4,788 \\
\hline Tinggi Tanaman 60 HSPT $(\mathrm{cm})$ & $*$ & ** & tn & 4,719 \\
\hline Tinggi Tanaman 90 HSPT $(\mathrm{cm})$ & $*$ & ** & th & 4,966 \\
\hline Diameter Pangkal Batang 30 HSPT (mm) & tn & tn & tn & 8,440 \\
\hline Diameter Pangkal Batang 60 HSPT (mm) & tn & tn & tn & 7,009 \\
\hline Diameter Pangkal Batang 90 HSPT (mm) & tn & tn & tn & 6,759 \\
\hline Panjang Akar (cm) & $*$ & tn & tn & 9,063 \\
\hline Berat Berangkasan Basah Tajuk (g) & tn & $*$ & tn & 14,238 \\
\hline Berat Berangkasan Basah Akar (g) & $* *$ & ** & tn & 18.103 \\
\hline Berat Berangkasan Kering Tajuk (g) & $*$ & tn & tn & 9,096 \\
\hline Berat Berangkasan Kering Akar (g) & tn & tn & tn & 7,818 \\
\hline
\end{tabular}

Keterangan : *: Berpengaruh nyata; **: Berpengaruh sangat nyata; tn: Berpengaruh tidak nyata; B: Pupuk Organik Cair; P: pupuk fosfat; BxP: Interaksi antara pupuk organik cair dan pupuk fosfat; KK: Koefisien Keragaman (\%)

Hasil uji $\mathrm{F}$ pada analisis ragam menunjukkan bahwa pupuk organik cair berpengaruh sangat nyata terhadap berat berangkasan basah akar, berpengaruh nyata terhadap tinggi tanaman umur 30, 60, 90 HSPT, panjang akar, berat berangkasan kering tajuk. Berpengaruh tidak nyata pada diameter pangkal batang, berat berangkasan basah tajuk dan berat berangkasan kering akar. Pertumbuhan bibit Kopi Arabika terbaik terdapat pada perlakuan pupuk organik cair konsentrasi $80 \mathrm{ml} / \mathrm{L}$ air. Dosis pupuk fosfat berpengaruh sangat nyata terhadap tinggi tanaman umur 60 dan 90 HSPT dan berat berangkasan basah akar, berpengaruh nyata terhadap berat berangkasan basah tajuk. Namun tidak berpengaruh pada tinggi tanaman umur 30 HSPT, diameter pangkal batang, panjang akar, berat berangkasan 
kering tajuk dan berat berangkasan kering akar. Pertumbuhan bibit Kopi Arabika terbaik terdapat pada perlakuan dosis pupuk fosfat 6 gram/polybag. Terdapat interaksi yang tidak nyata antara konsentrasi pupuk organik cair dan dosis pupuk fosfat pada semua parameter

\section{Pengaruh Konsentrasi Pupuk Organik Cair terhadap Pertumbuhan Bibit Kopi}

Rata-rata pertumbuhan bibit kopi akibat perlakuan konsentrasi pupuk organik cair dapat dilihat pada Tabel 2 .

Tabel 2. Rata-rata pertumbuhan bibit kopi akibat perlakuan konsentrasi pupuk organik cair

\begin{tabular}{|c|c|c|c|c|}
\hline \multirow[b]{2}{*}{ Parameter } & \multicolumn{3}{|c|}{ Pupuk Organik Cair Buah-buahan } & \multirow[b]{2}{*}{ BNJ 0,05} \\
\hline & $\begin{array}{c}\text { Kontrol } \\
\left(\mathrm{B}_{0}\right)\end{array}$ & $\begin{array}{c}40 \mathrm{ml} / \mathrm{L} \\
\text { air } \\
\left(\mathrm{B}_{1}\right)\end{array}$ & $\begin{array}{c}80 \mathrm{ml} / \mathrm{L} \\
\text { air } \\
\left(\mathrm{B}_{2}\right)\end{array}$ & \\
\hline Tinggi Tanaman 30 HSPT $(\mathrm{cm})$ & $12,74 \mathrm{a}$ & $12,72 \mathrm{a}$ & $13,44 \mathrm{a}$ & 0,74 \\
\hline Tinggi Tanaman 60 HSPT $(\mathrm{cm})$ & $13,67 \mathrm{a}$ & $13,54 \mathrm{a}$ & $14,48 \mathrm{~b}$ & 0,73 \\
\hline Tinggi Tanaman 90 HSPT $(\mathrm{cm})$ & $15,15 \mathrm{a}$ & $15,13 \mathrm{a}$ & $16,24 \mathrm{~b}$ & 0,87 \\
\hline Diameter Pangkal Batang 30 HSPT (mm) & 2,58 & 2,58 & 2,54 & - \\
\hline Diameter Pangkal Batang 60 HSPT (mm) & 2,62 & 2,57 & 2,63 & - \\
\hline Diameter Pangkal Batang 90 HSPT (mm) & 2,64 & 2,65 & 2,67 & - \\
\hline Panjang Akar (cm) & $11,50 \mathrm{a}$ & $12,13 \mathrm{ab}$ & $12,91 \mathrm{~b}$ & 1,31 \\
\hline Berat Berangkasan Basah Tajuk (g) & 2,56 & 2,87 & 2,97 & - \\
\hline Berat Berangkasan Basah Akar (g) & $1,03 \mathrm{a}$ & $1.19 \mathrm{~b}$ & $1,15 \mathrm{~b}$ & 0,073 \\
\hline Berat Berangkasan Kering Tajuk (g) & $0,72 \mathrm{a}$ & $0,81 \mathrm{~b}$ & $0,79 \mathrm{ab}$ & 0,083 \\
\hline Berat Berangkasan Kering Akar (g) & 0,20 & 0,20 & 0,23 & - \\
\hline
\end{tabular}

Tabel 2 menunjukkan bahwa, rata-rata tinggi tanaman bibit kopi pada umur 30, 60 dan 90 HSPT lebih baik terdapat pada perlakuan konsentrasi $80 \mathrm{ml} /$ air $\left(\mathrm{B}_{2}\right)$ yang berbeda tidak nyata pada umur 30 HSPT, pada umur 60 dan 90 HSPT berbeda nyata dengan perlakuan kontrol $\left(\mathrm{B}_{0}\right)$ dan konsentrasi $40 \mathrm{ml} /$ air $\left(\mathrm{B}_{1}\right)$. Panjang akar bibit kopi terbaik terdapat pada perlakuan pupuk organik cair konsentrasi $80 \mathrm{ml} /$ air $\left(\mathrm{B}_{2}\right)$ yang berbeda nyata dengan perlakuan kontrol $\left(\mathrm{B}_{0}\right)$ namun tidak berbeda nyata dengan perlakuan konsentrasi $40 \mathrm{ml} / \mathrm{air}$ $\left(\mathrm{B}_{1}\right)$. Berat berangkasan basah akar bibit kopi berpengaruh sangat nyata dan perlakuan lebih baik dijumpai pada konsentrasi pupuk organik cair $40 \mathrm{ml} /$ air $\left(\mathrm{B}_{1}\right)$ yang berbeda nyata terhadap perlakuan kontrol $\left(\mathrm{B}_{0}\right)$, namun tidak berbeda nyata dengan perlakuan konsentrasi 80 $\mathrm{ml} /$ air $\left(\mathrm{B}_{2}\right)$. Berat berangkasan kering tajuk bibit kopi berpengaruh nyata dan perlakuan lebih baik dijumpai pada konsentrasi pupuk organik cair $40 \mathrm{ml} /$ air $\left(\mathrm{B}_{1}\right)$ yang berbeda nyata terhadap perlakuan kontrol $\left(\mathrm{B}_{0}\right)$, namun tidak berbeda nyata dengan perlakuan konsentrasi 80 $\mathrm{ml} /$ air $\left(\mathrm{B}_{2}\right)$.

\section{Pengaruh Dosis Pupuk Fosfat Terhadap Pertumbuhan Bibit Kopi}

Rata-rata pertumbuhan bibit kopi akibat perlakuan dosis pupuk fosfor dapat dilihat pada Tabel 3.

Tabel 3 menunjukkan bahwa, rata-tara tinggi tanaman bibit kopi Pada umur 60 dan 90 HSPT berpengaruh sangat nyata pada dosis pupuk fosfor $6 \mathrm{~g} /$ polibag $\left(\mathrm{P}_{3}\right)$ yang berbeda nyata terhadap perlakuan dosis pupuk fosfor $2 \mathrm{~g} /$ polibag $\left(\mathrm{P}_{1}\right)$ namun berbeda tidak nyata terhadap perlakuan dosis pupuk fosfor $4 \mathrm{~g} /$ polibag $\left(\mathrm{P}_{2}\right)$. Berat berangkasan basah tajuk bibit kopi berpengaruh nyata akibat dosis pupuk fosfor pada dosis $6 \mathrm{~g} /$ polibag $\left(\mathrm{P}_{3}\right)$ yang berbeda nyata dengan perlakuan dosis $2 \mathrm{~g} /$ polibag $\left(\mathrm{P}_{1}\right)$ namun berbeda tidak nyata terhadap perlakuan dosis $4 \mathrm{~g} /$ polibag $\left(\mathrm{P}_{2}\right)$. Berat berangkasan basah akar bibit kopi berpengaruh sangat nyata akibat 
dosis pupuk pada dosis $6 \mathrm{~g} /$ polibag $\left(\mathrm{P}_{3}\right)$ yang berbeda nyata terhadap perlakuan dosis 2 $\mathrm{g} /$ polibag $\left(\mathrm{P}_{1}\right)$ namun berbeda tidak nyata dengan perlakuan dosis $4 \mathrm{~g} /$ polibag $\left(\mathrm{P}_{2}\right)$.

Tabel 3. Rata-rata pertumbuhan bibit kopi akibat perlakuan dosis pupuk fosfor

\begin{tabular}{|c|c|c|c|c|}
\hline \multirow[t]{2}{*}{ Parameter } & \multicolumn{3}{|c|}{ Dosis Pupuk Fosfor } & \multirow[b]{2}{*}{ BNJ 0,05} \\
\hline & $\begin{array}{c}2 \\
\mathrm{~g} / \text { polibag } \\
\left(\mathrm{P}_{1}\right)\end{array}$ & $\begin{array}{c}4 \\
\mathrm{~g} / \text { polibag } \\
\left(\mathrm{P}_{2}\right)\end{array}$ & $\begin{array}{c}6 \\
\text { g/polibag } \\
\left(\mathrm{P}_{3}\right)\end{array}$ & \\
\hline Tinggi Tanaman 30 HSPT $(\mathrm{cm})$ & 12,63 & 13,28 & 13,00 & - \\
\hline Tinggi Tanaman 60 HSPT $(\mathrm{cm})$ & $13,26 \mathrm{a}$ & $14,26 \mathrm{~b}$ & $14,17 \mathrm{~b}$ & 0,73 \\
\hline Tinggi Tanaman 90 HSPT $(\mathrm{cm})$ & $14,59 \mathrm{a}$ & $15,78 \mathrm{~b}$ & $16,15 b$ & 0,87 \\
\hline Diameter Pangkal Batang 30 HSPT (mm) & 2,55 & 2,51 & 2,65 & - \\
\hline Diameter Pangkal Batang 60 HSPT (mm) & 2,58 & 2,53 & 2,71 & - \\
\hline Diameter Pangkal Batang 90 HSPT (mm) & 2,61 & 2,61 & 2,75 & - \\
\hline Panjang Akar (cm) & 12,3 & 12,39 & 11,85 & - \\
\hline Berat Berangkasan Basah Tajuk (g) & $2,49 \mathrm{a}$ & $2,81 \mathrm{ab}$ & $3,10 \mathrm{~b}$ & 0,47 \\
\hline Berat Berangkasan Basah Akar (g) & $1,01 \mathrm{a}$ & $1,11 \mathrm{~b}$ & $1,15 \mathrm{~b}$ & 0,073 \\
\hline Berat Berangkasan Kering Tajuk (g) & 0,72 & 0,79 & 0,8 & - \\
\hline Berat Berangkasan Kering Akar (g) & 0,2 & 0,21 & 0,22 & - \\
\hline
\end{tabular}

\section{Interkasi antara Konsentrasi Pupuk Organik Cair Buah-Buahan dengan Fosfor terhadap Pertumbuhan Bibit Kopi Arabika}

Hasil penelitian menunjukkan bahwa terdapat interaksi yang tidak nyata antara perlakuan konsentrasi pupuk organik cair buah-buahan dengan dosis pupuk fosfor terhadap parameter tinggi tanaman umur 30, 60, dan 90 HSPT, diameter pangkal batang umur 30, 60, dan 90 HSPT, panjang akar, berat berangkasan basah tajuk, berat berangkasan basah akar, berat berangkasan kering tajuk, dan berat berangkasan kering akar.

\section{Pembahsan}

\section{Pengaruh Konsentrasi Pupuk Organik Cair terhadap Pertumbuhan Bibit Kopi}

Hasil penelitian menunjukkan bahwa konsentrasi pupuk organik cair buah-buahan berpengaruh sangat nyata terhadap berat berangkasan kering akar, berpengaruh nyata terhadap tinggi tanaman umur 30, 60 ,dan 90 HSPT, panjang akar dan berat berangkasan kering tajuk, berpengaruh tidak nyata terhadap diameter pangkal batang umur 30, 60, 90 HSPT, berat berangkasan basah tajuk, dan berat berangkasan basah akar.

Bibit kopi tertinggi pada umur 30 HSPT terdapat pada perlakuan konsentrasi $80 \mathrm{ml} / \mathrm{L}$ air yang berbeda tidak nyata akibat perlakuan kontrol dan $40 \mathrm{ml} / \mathrm{L}$ air. Sedangkan pada umur 60 dan 90 HSPT terdapat pada perlakuan konsentrasi $80 \mathrm{ml} / \mathrm{L}$ air berbeda nyata dengan perlakuan kontrol dan konsentrasi $40 \mathrm{ml} / \mathrm{L}$ air. Hal ini menunjukkan bahwa semakin tinggi konsentrasi pupuk organik cair yang diberikan semakin banyak pula ketersediaan unsur hara bagi tanaman, pupuk organik cair termasuk pupuk yang kandungan unsur haranya dilepas secara langsung dan dapat diserap oleh tanaman

Menurut Harjono (2017), pupuk organik cair lebih mudah diserap oleh tanaman karena unsur-unsur didalamnya sudah terurai. Hasil penelitian Dewantara et al., (2015), menunjukkan bahwa perlakuan pupuk organik cair dari buah dan sayuran berpengaruh nyata pada peubah tinggi tanaman dengan perlakuan konsentrasi $40 \mathrm{ml} / \mathrm{L}$ air. Selanjutnya hasil penelitian Deby (2011), menunjukkan bahwa pemberian pupuk organik cair dari buah konsentrasi $50 \mathrm{ml} / \mathrm{L}$ air memberikan pengaruh sangat nyata pada bibit tanaman kopi. 
Hasil penelitian ini menunjukkan bahwa rata-rata diameter batang pada umur 30, 60, dan 90 HSPT berpengaruh tidak nyata akibat konsentrasi pupuk organik cair. Diduga hal tersebut disebabkan karena tanaman kopi membutuhkan waktu yang cukup lama dalam pertumbuhan diameter batang. Seperti yang diungkapkan oleh Ardiyani (2015), bahwa tanaman tahunan seperti kopi membutuhkan waktu yang cukup lama dalam meningkatkan pertumbuhan diameter batang.

Hasi penelitian menunjukkan bahwa rata-rata panjang akar bibit kopi berpengaruh nyata akibat konsentrasi pupuk organik cair. Perlakuan yang lebih baik terdapat pada perlakuan konsentrasi $80 \mathrm{ml} / \mathrm{L}$ air yang berbeda nyata dengan perlakuan kontrol namun tidak berbeda nyata dengan perlakuan konsentrasi $40 \mathrm{ml} /$ air. Hal ini menunjukkan bahwa pupuk organik mempunyai peran penting bagi tanah yaitu untuk menggemburkan lapisan tanah permukaan, meningkatkan daya serap dan daya simpan air yang secara keseluruhan akan meningkatkan kesuburan tanah dapat memudahkan pertumbuhan akar untuk menyerap unsur hara. Hal ini sesuai dengan Laviendi et al., (2015) yang menjelaskan bahwa penggunaan pupuk organik dapat memberikan beberapa manfaat yaitu menyediakan unsur hara makro dan mikro bagi tanaman, menggemburkan tanah, memperbaiki tekstur dan struktur tanah, memudahkan pertumbuhan akar tanaman, daya serap air yang lebih lama pada tanah.

Hasi penelitian ini menunjukkan bahwa rata-rata berat berangkasan basah tajuk bibit tanaman kopi berpengaruh tidak nyata akibat perlakuan pupuk organik cair. Hal ini disebabkan tanaman masih sangat muda sehingga jumlah daun masih sedikit untuk menjalankan aktivitas fotosintesis. Nilai nisbah luas daun berhubungan dengan bobot basah tajuk tanaman. Bila nilai luas daun naik maka akan menyebabkan laju asimilasinya naik dan menghasilkan berat basah yang tinggi. Menurut Suryati et al., (2015) bahwa semakin meningkat luas daun maka akan meningkat pula aktivitas fotosintesis menghasilkan asimilat lebih banyak yang akan mengandung berat basah tanaman.

Hasi penelitian ini menunjukkan bahwa rata-rata berat berangkasan kering tajuk bibit tanaman kopi berpengaruh nyata dan perlakuan lebih baik dijumpai pada konsentrasi pupuk organik cair $40 \mathrm{ml} / \mathrm{L}$ air yang berbeda nyata terhadap perlakuan kontrol namun tidak berbeda nyata dengan perlakuan konsentrasi $80 \mathrm{ml} / \mathrm{L}$ air. Diduga bahwa kandungan pupuk cair dari buah mampu memenuhi kebutuhan unsur hara khususnya fosfor pada bibit kopi. Kandungan $\mathrm{P}$ dalam pupuk organik cair dari buah yang siap digunakan oleh tanaman. Didukung juga dengan pendapat Lakitan (2000) yang menyatakan bahwa hasil fotosintesis pada daun banyak ditranslokasikan ke bagian tajuk dan bagian perakaran tanaman.

Hasi penelitian ini menunjukkan bahwa rata-rata berat berangkasan basah akar bibit tanaman kopi berpengaruh sangat nyata dan perlakuan lebih baik dijumpai pada konsentrasi pupuk organik cair $80 \mathrm{ml} / \mathrm{L}$ air yang berbeda nyata terhadap perlakuan kontrol namun tidak berbeda nyata dengan perlakuan konsentrasi $40 \mathrm{ml} / \mathrm{L}$ air. Hal ini diduga akibat peranan unsur hara dalam pupuk organik cair terhadap pertumbuhan akar menyerap unsur hara dari dalam tanah. Hal ini sejalan dengan pendapat Sutedjo (2002) dalam Sianturi (1999), yang menyatakan bahwa unsur hara makro yang tersedia dalam jumlah yang cukup akan meningkatkan perkembangan perakaran.

\section{Pengaruh Dosis Pupuk Fosfor terhadap Pertumbuhan Bibit Kopi}

Hasil penelitian ini menunjukkan bahwa, rata-tara tinggi tanaman bibit kopi pada umur 30 HSPT lebih baik dijumpai pada perlakuan dosis pupuk fosfor $4 \mathrm{~g} /$ polibag. Namun secara statistik berpengaruh tidak nyata pada parameter tinggi tanaman. Hal ini diduga bahwa pupuk yang diberikan belum terurai sehingga belum dapat diserap oleh tanaman.

Tinggi bibit kopi pada umur 60 dan 90 HSPT tinggi bibit kopi berpengaruh sangat nyata, perlakuan terbaik dijumpai pada perlakuan dosis pupuk fosfor $6 \mathrm{~g} /$ polibag yang 
berbeda nyata terhadap perlakuan dosis pupuk fosfor $2 \mathrm{~g} /$ polibag namun berbeda tidak nyata terhadap perlakuan dosis pupuk fosfor $4 \mathrm{~g} /$ polibag, hal tersebut diduga akibat peranan unsur $\mathrm{P}$ yang sangat berpengaruh bagi tanaman.

Fosfor berperan dalam pertumbuhan dan perkembangan tanaman, terutama berguna pada tanaman masih dalam tahap pembibitan. Unsur ini berperan dalam mempercepat pertumbuhan akar sehingga tanaman dapat lebih cepat menyerap unsur hara dan air yang dibutuhkan pada awal pertumbuhan. Selain itu, fosfor berperan juga dalam hal memperkuat batang tanaman. Menurut Rosmarkam dan Yuwono (2002), Fosfor memegang peranan penting dalam fotosintesis, perkembangan tanaman dan pertumbuhan akar. Jika kekurangan unsur P maka volume jaringan tanaman akan menjadi lebih kecil dan warna daun menjadi lebih gelap.

Kemudian menurut Rinsema (1986), bahwa unsur P berperan dalam merangsang pertumbuhan akar, bunga dan pemasakan buah serta berperan penting sebagai penyusun inti sel lemak dan protein tanaman (Rinsema, 1986). Hasil penelitian menunjukkan bahwa ratarata diameter batang pada umur 30, 60, dan 90 HSPT berpengaruh tidak nyata akibat dosis pupuk fosfor. Diduga hal tersebut karena tanaman kopi membutuhkan waktu yang cukup lama dalam pertumbuhan diameter batang. Seperti yang diungkapkan oleh Ardiyani (2015), bahwa tanaman tahunan seperti kopi membutuhkan waktu yang cukup lama dalam meningkatkan pertumbuhan diameter batang.

Hasil penelitian menunjukkan bahwa rata-rata berat berangkasan kering tajuk dan akar berpengaruh tidak nyata akibat dosis pupuk fosfor. Gardner et al. (1991) menyatakan berat kering merupakan akibat dari penimbunan hasil bersih dari asimilasi CO2 sepanjang musim pertumbuhan yang mencerminkan akumulasi senyawa organik yang berhasil disintesis tanaman dari senyawa anorganik terutama air dan CO2. Menurut pernyataan tersebut, hasil penlitian ini diduga masa untuk mengakumulasi senyawa organik belum cukup maksimal.

\section{Interkasi antara Konsentrasi Pupuk Organik Cair Buah-buahan dengan Fosfor terhadap Pertumbuhan Bibit Kopi Arabika}

Hasil penelitian menunjukkan bahwa terdapat interaksi yang tidak nyata antara perlakuan konsentrasi pupuk organik cair buah-buahan dengan fosfor. Hal ini disebabkan karena perbedaan pertumbuhan bibit kopi arabika akibat konsentrasi pupuk organik cair dari buah pada taraf yang berbeda tidak dipengaruhi oleh dosis pupuk fosfor dan begitu juga dengan perbedaan perlakuan dosis pupuk fosfor tidak dipengaruhi oleh konsentrasi pupuk organik cair. Hal ini terjadi karena kedua faktor tersebut tidak saling mendukung pertumbuhan bibit Kopi Arabika.

\section{KESIMPULAN DAN SARAN}

\section{Kesimpulan}

Perlakuan pupuk organik cair dari buah-buahan berpengaruh sangat nyata terhadap berat berangkasan basah akar, berpengaruh nyata terhadap pertumbuhan tinggi tanaman umur 30, 60, dan 90 HSPT, panjang akar, berat berangkasan kering tajuk. Pertumbuhan bibit kopi arabika terbaik terdapat pada perlakuan konsentrasi $80 \mathrm{ml} / 1$ air. Perlakuan pupuk fosfor berpengaruh sangat nyata terhadap tinggi tanaman umur 60 dan 90 HSPT dan berat berangkasan basah akar, berpengaruh nyata terhadap berat berangkasan basah tajuk, pertumbuhan bibit Kopi Arabika terbaik terdapat pada perlakuan dosis $6 \mathrm{~g} /$ polibag. Terdapat interaksi yang tidak nyata antara konsentrasi pupuk organik cair dan dosis pupuk fosfor pada semua parameter yang diamati. 


\section{Saran}

Perlu dilakukan penelitian lanjutan dan analisis pupuk organik cair dari buah-buahan dan sosialisasi ke petani untuk pemanfaatan pupuk organik cair dari buah-buahan.

\section{DAFTAR PUSTAKA}

Ardiyani, F. 2015. Morphological Characterization and Identification of Coffea Liberica Callus of Somatik Embryogenesis Propagation. J. Pelita Perkebunan 31 (2) : 81-89.

Arif, F. E. dan Wibowo. 2013. Peran Pupuk Nitrogen dalam Pertumbuhan dan Hasil Stevia. Makalah Seminar Umum. UGM. Yogyakarta.

Deby, M. 2011. Pemberian Pupuk Organik Cair terhadap Pertumbuhan Bibit Kopi (Coffea sp.). Karya Ilmiah Program Diploma III. Politeknik Pertanian Negeri Samarinda. Samarinda.

Dewantara, F. Rian., J. Ginting dan Irsal. 2015. Respon pertumbuhan bibit kopi robusta (Coffea robusta L.) terhadap berbagai media tanam dan pupuk organik cair. Medan. Jurnal Agroteknologi FP USU 5 (3) : 676-684.

Falahuddin, I., A. R. Puji. dan L. Harmeni. 2016. Pengaruh Pupuk Organik Limbah Kulit Kopi (Coffea arabica L.) terhadap Pertumbuhan Bibit Kopi. UIN Raden Fatah. Palembang. J. Bioilmi 2 (2) : 108-120.

Gardner, P., B. Pearce, L. Mitchell. 2008. Fisiologi Tanaman Budidaya. UGM Press.

Hanolo, W. 1997. Tanggapan Tanaman Selada dan Sawi terhadap Dosis dan Cara Pemberian Pupuk Cair Stimulan. J. Agrotropika. 1 (1):25-29.

Harjono, A. P. 2017. Pengaruh Berbagai Konsentrasi Pupuk Organik Cair (POC) terhadap Pertumbuhan Tanaman Bayam Hijau. Skripsi. Unversitas Sanata Dharma. Yogyakarta.

Isnaini, M. 2006. Pertanian Organik. Kreasi Wacana. Yogyakarta.

Lakitan. 2000. Budidaya Tanaman Sayuran dengan Sistem Hidroponik. Bandung. Balai

Penelitian Tanaman dan Sayuran.

Laviendi, A. Jonatan, G. Irsal. 2015. Pengaruh perbandingan media tanam kompos kulit biji kopi dan pemberian pupuk NPK (15:15:15) terhadap pertumbuhan bibit kopi (Coffea arabica L.) di rumah kaca. J. Agroteknologi FP USU. 5 (1) : 72-77.

Lingga, P. dan Marsono. 2004. Petunjuk Penggunaan Pupuk. Redaksi Agromedia. Jakarta.

Lubis, A. R., L. Mawarni \& R. Sipayung. Respon Pertumbuhan Bibit Kopi Robusta (Coffea robusta L.) terhadap Pemberian Pupuk Kandang Ayam dan Pupuk Organik Cair. J. Agroteknologi FP USU. 5 (88):692-696.

Mawardi, S. 2008. Panduan Budidaya dan Pengolahan Kopi Arabika Gayo. Pusat Penelitian Kopi dan Kakao Indonesia. Banda Aceh.

Najiyati, S. dan Danarti. 2010. Budidaya Kopi dan Pengolahan Pasca Panen. Penebar Swadaya. Jakarta.

Rinsema. 1986. Dasar-dasar Ilmu Tanah. PT. Raja Grafindo Persada. Jakarta.

Rizqiani, N., F.A. Erlina \& W. Y. Nasih.2007. Pengaruh Dosis dan Frekuensi Pemberian Pupuk Organik Cair terhadap Pertumbuhan dan Hasil Buncis. J. Ilmu Tanah dan Lingkungan. 7 (1):43-45.

Rosmarkam, A. dan N. W. Yuwono. 2002. Ilmu Kesuburan Tanah. Kanisius. Yogyakarta.

Suryani. 1999. Pengantar Ilmu Agronomi. Agromedia. Jakarta.

Sutedjo, M. M. 1986. Pupuk dan Cara Pemupukan. Bina Aksara. Jakarta.

Widawati, S., dan Kanti, S. A. 2000. Pengaruh Isolat Bakteri Pelarut Fosfat (BPF) Efektif dan Dosis Pupuk Fosfat terhadap Pertumbuhan Kacang Tanah (Arachis hypogaea). Lembaga Ilmu Pengetahuan Indonesia. 